\title{
The tilt illusion: Length and luminance changes of induction line and third (disinhibiting) line
}

\author{
BRIAN I. O'TOOLE \\ University of Sydney, Sydney, 2006, New South Wales, Australia
}

\begin{abstract}
Direct effects (acute-angle expansion) and indirect effects (acute angle contraction) aspects of the tilt illusion were reduced by reductions in the length as well as the luminance of the induction line, and also by the addition of a third line to the display. When this third (disinhibiting) line was also reduced in length and luminance, the reduction in the illusion became less and the illusion increased in magnitude. The illusion size was also changed by increasing the orientation difference between the disinhibiting line and the induction line. It is argued that these effects are mediated by (lateral) inhibition and disinhibition between mechanisms responsible for orientation coding in the visual system.
\end{abstract}

The perceived orientation of a line (test, or $\mathrm{T}$ line) may be changed when another line (induction, or I line) of a different orientation is presented simultaneously, an effect called the tilt illusion. The direction of change is away from the $I$ line if the difference in relative orientation between $I$ and $T$ lines is approximately $0^{\circ}$ and $50^{\circ}$ (acute-angle expansion, or the direct effect) and towards the I line if the difference is between approximately $50^{\circ}$ and $90^{\circ}$ (acute-angle contraction, nr the indirect effect) (Gibson, 1937; Logan, 1962; Over, Broerse, \& Crassini, 1972; O'Toole \& Wenderoth, 1977). Similar effects, called tilt aftereffects, occur when the $I$ and $T$ lines are presented successively rather than simultaneously (Gibson \& Radner, 1937; Logan, 1962; Muir \& Over, 1970).

A simple extension of the Carpenter and Blakemore (1973) model of interaction between cortical units responsive to orientation has been presented earlier to explain both indirect and direct effects in the tilt illusion (O'Toole \& Wenderoth, 1977). It was suggested that direct effects might be due to lateral inhibition, whereas indirect effects might be due to lateral disinhibition in the orientation domain. If this is the case, then increases in the size of the direct

This work was supported by a University research grant to the University of Sydney in 1976. Grateful thanks are extended to Mr. Chris Edwards, who helped design the apparatus, and to Mr. Warren Davies, who built it. The author has benefited greatly from discussion with Dr. Ian Curthoys and especially from Dr. Peter Wenderoth, who has maintained interest in the research and commented critically upon various forms of the manuscript. The main findings were reported to the Fourth Australian Experimental Psychology Conference, Newcastle University, N.S.W., in May 1977. Correspondence concerning the work reported should be addressed to the author, care of the Department of Psychology, Sydney University, Sydney, N.S.W. 2006, Australia. effect may result from increased inhibitory influence of $I$ on $T$, whereas increases in the indirect effect may result from increased disinhibitory influence of $I$ on $T$. If inhibitory influence of $I$ on $T$ is a function of activity of the units responsive to $I$, then increasing the output of these units might result in increasing inhibitory interactions (e.g., Hartline \& Ratliff, 1957) and therefore increased direct effect magnitude. Similarly, increasing output of units responsive to the I line might result in increased disinhibitory interactions and therefore increased magnitude of the indirect effect. This increased inhibitory and disinhibitory influence may come about in a number of ways. Reductions in length of stimuli have been shown to reduce output of orientationsensitive cells in the visual cortex of cats (Henry, Bishop, \& Dreher, 1974; Henry, Dreher, \& Bishop, 1974), as have reductions in luminance (Bisti, Clement, Maffei, \& Mecacci, 1977; Hoeppner, 1974), without changing the orientation at which peak responses occur. Henry, Dreher, and Bishop (1974), for complex cells, and Henry, Bishop, and Dreher (1974), for simple and hypercomplex cells (Type I) of the cat visual cortex, found that changing the length of a line or bar stimulus changed the orientation tuning curve. When the stimulus was a long bar (up to approximately $4^{\circ}$ visual angle), the tuning curve was unimodal, with a sharp peak and large drop-off to either side of the best orientation of the cell. For shorter bars, the tuning curve became flatter with a lower peak (at the same orientation) and broader or less steep dropoff to either side of the best orientation. This lower output at the same best orientation should lead to smaller inhibitory input to other units and consequently larger firing rates of these units in relation to their firing rates in the presence of a longer bar. Thus, 
the psychophysical implications are clear: Reductions in length of induction stimuli might result in reductions in magnitude of direct and indirect tilt illusions.

Changes in length of induction stimuli have been shown to affect the sizes of illusions (Oyama, 1975; Wallace, 1969; Wenderoth, O'Toole, \& Curthoys, 1975), as well as aftereffect (Nakayama \& Roberts, 1972) and masking (Parlee, 1969). Nakayama and Roberts (1972) adapted subjects to either a blank field or one of two moving gratings, and measured contrast threshold for detection of a shortline grating. They reported a significant difference between threshold elevation for a short-line grating following adaptation to a short-line grating, a longline grating, or a blank field, with adaptation to the short-line grating producing highest threshold elevation. Unfortunately, they used an incomplete design, failing to test threshold elevation with a long-line grating. Parlee (1969) varied the length of lines in her masking experiment and found maximum masking when the masking line was slightly longer than the target line (approximately 135\%; see Parlee, 1969, Figure 3), with masking decreasing for longer or shorter lines. Oyama (1975) and Wallace (1969) increased the lengths of transversals of the Zöllner illusion (of which the tilt illusion is a variant; Day, 1965) and found increases in the magnitude of the direct effect up to a length of approximately $45 \mathrm{~min}$ of arc visual angle (Oyama) or $1^{\circ}$ visual angle (Wallace). Wenderoth et al. (1975) increased the length of the I line in the tilt illusion and found corresponding increases in the magnitude of the direct effect until the point at which the I line length equaled the $T$ line length. This was, however, a preliminary study and possibly was confounded by methodological artifacts. Apart from this, no study has been reported in which the lengths of both $I$ and $T$ lines have been systematically varied and the effect on both the direct and indirect aspects of the tilt illusion has been measured.

\section{EXPERIMENT 1}

The aim of the first experiment, then, was to investigate the effects of length changes in both the $I$ and the $T$ line for two orientations of $I$ relative to $T$, that are known to elicit direct and indirect effects (O'Toole \& Wenderoth, 1977).

\section{Method}

Induction lines in the present experiments were constructed by laying strips of yellow PVC tape upon black magnetized rubber, which was then set upon a circular metal disk (Wenderoth \& Beh, 1977). Through the center of this disk passed a shaft bearing a metal rod, $52 \mathrm{~mm}$ in length and $2 \mathrm{~mm}$ in width and driven by a reversible synchronous motor that drove the rod at a constant angular velocity of $2^{\circ} / \mathrm{sec}$. This rod was nominated as the $\mathrm{T}$ line. Laterally displaced to the left of the $T$ line was another rod of the same dimensions driven by a similar motor. Counterweights attached to the motors ensured smooth movement. The center of the rod (its center of rotation) could be positioned from 75 to $160 \mathrm{~mm}$ from the center of the $T$ line, both centers lying on the same horizontal plane. The second rod was nominated as the comparison, or $\mathrm{C}$ line. Both rods were coated with a yellow phosphorescent powder. Viewed in complete darkness under continuous ultraviolet illumination against the flat black of the apparatus, the contrasts of all stimuli were virtually 1.0 (where contrast is defined as the ratio of luminance difference to twice the average luminance). As the experiments reported were carried out at different times, luminances of $I, T$, and $C$ varied due to changes in the ultraviolet source; however, all luminances were measured both before and after each series and will be reported later. The stimulus configuration appears in Figure 1a.

Procedure. The observer, whose head was positioned in a bite bar of dental compound, viewed the display binocularly through a black seamless viewing tube, the center of which was on the same horizontal plane as the centers of $T$ and $C$, and moved either $T$ or $C$ by means of two three-position switches connected to the synchronous motors. Subjects' view of the display was occluded (except during settings) by a shutter manually operated by the experimenter. The experimenter sat behind the apparatus and read subjects' settings from each of two protractors rigidly attached to the shafts of $T$ and C. Four start positions of the subject-adjustable stimuli were used for all experiments $- \pm 5^{\circ}$ and $\pm 7.5^{\circ}$ relative to true alignment $(+$ indicates clockwise rotation)-to control for any start position biasing effects (Wenderoth, Rodger, \& Curthoys, 1968).

The sizes of the direct and indirect effects, respectively, were measured for orientations of I relative to $T$ of $20^{\circ}$ and $70^{\circ}$, as a function of $T$ - and I-line lengths of $.5^{\circ}, 1.0^{\circ}$, and $2.0^{\circ}$ visual angle. The different lengths were made possible by partial occlusion of $\mathrm{T}$ or I with strips of black PVC tape. T was always vertical, and the distance between the centers of $T$ and $C$ was $3.83^{\circ}$ visual angle. A control experiment (not reported), which varied the lengths of $\mathrm{T}$ and $\mathrm{C}$ for constant $\mathrm{I}$ lengths showed no significant effect in the size of the direct effect for changes in $\mathrm{C}$-line length; however, the maximum illusion sizes occurred for equal $T$ and $C$ lengths. Consequently, $\mathrm{T}$ and $\mathrm{C}$ were equated for length for all experiments.

The subjects' task was to set $C$ parallel to $T$ in a pretest/test paradigm: settings were made in the absence (no I line, pretest) and
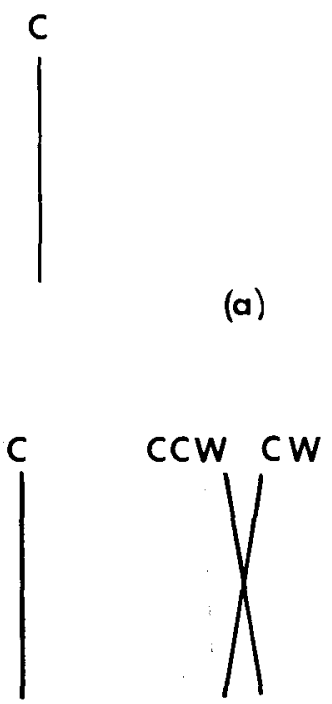

(b)

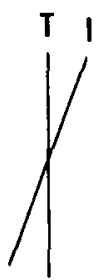

(a)
Figure 1. Illustration of stimulus configurations used in Experiment 1 (a) and Experiment 2 (b). 
Table 1

Effects of T-and I-Line Length Changes (in Degrees) on the Tilt Illusion

\begin{tabular}{|c|c|c|c|c|c|c|c|c|c|c|c|c|}
\hline \multirow{4}{*}{$\begin{array}{l}\text { I-Line } \\
\text { Length }\end{array}$} & \multicolumn{12}{|c|}{ T-Line Length } \\
\hline & \multicolumn{6}{|c|}{ Direct Effect (I = $20 \mathrm{deg})$} & \multicolumn{6}{|c|}{ Indirect Effect $(\mathrm{I}=70 \mathrm{deg})$} \\
\hline & \multicolumn{2}{|c|}{.5} & \multicolumn{2}{|c|}{1.0} & \multicolumn{2}{|c|}{2.0} & \multicolumn{2}{|c|}{.5} & \multicolumn{2}{|c|}{1.0} & \multicolumn{2}{|c|}{2.0} \\
\hline & Mean & SE & Mean & SE & Mean & SE & Mean & SE & Mean & SE & Mean & $\mathrm{SE}$ \\
\hline $\begin{array}{r}.5 \\
1.0 \\
2.0\end{array}$ & $\begin{array}{l}-.26 \\
-1.03 \\
-1.58\end{array}$ & $\begin{array}{l}.27 \\
.23 \\
.19\end{array}$ & $\begin{array}{l}-.47 \\
-.66 \\
-1.27\end{array}$ & $\begin{array}{l}.12 \\
.19 \\
.17\end{array}$ & $\begin{array}{l}-.33 \\
-.46 \\
-.94\end{array}$ & $\begin{array}{l}.09 \\
.13 \\
.15\end{array}$ & $\begin{array}{l}.31 \\
.16 \\
.38\end{array}$ & $\begin{array}{l}.10 \\
.15 \\
.12\end{array}$ & $\begin{array}{l}.06 \\
.28 \\
.25\end{array}$ & $\begin{array}{l}.11 \\
.07 \\
.11\end{array}$ & $\begin{array}{r}-.05 \\
.16 \\
.52\end{array}$ & $\begin{array}{l}.09 \\
.10 \\
.06\end{array}$ \\
\hline
\end{tabular}

Note-Since I was oriented $C W(+)$ from $T$, the direction of direct effects is negative, and that of indirect effects, positive.

then in the presence (I line visible, test) of ultraviolet illumination. The subjects were instructed to fixate the center of $T$ and $I$ and were permitted to bracket. The subjects were given rest periods of $2 \mathrm{~min}$ with the overhead lights on after every eight settings to allow for the dissipation of any aftereffects that may have built up.

Design. A 3 by 3 randomized block factorial design was employed, with start positions randomized within each block. Two groups of subjects were observed under all nine blocks, each representing some conjunction of $I$ and $T$ lengths. One group received an I-T separation of $20^{\circ}$, the other of $70^{\circ}$. Fifteen subjects were assigned randomly to each group.

Subjects. All subjects used in the following experiments were drawn from an introductory course in psychology at the University of Sydney, where nominal credit towards their final mark in Psychology I could be gained by participating a certain number of hours in on-going experiments in the department. All were naive to the aims of the experiments, and all were emmetropic or had corrected vision.

Luminance and contrast. The lumiances of $\mathrm{C}, \mathrm{T}, \mathrm{I}$, and background were $6.42,5.11,4.39$, and $.028 \mathrm{~cd} / \mathrm{m}^{2}$, respectively, each measured with a Pritchard Spectra photometer with a 6-min of arc aperture, except for the background, for which a $2^{\circ}$ aperture was used (which gives a lower limit of $.0001 \mathrm{fL}$ ). Thus, the contrasts of the stimuli were $.991, .989$, and .987 , respectively. The luminances of $T$ and $C$ decayed to $16.5 \%$ of their fully illuminated value $15 \mathrm{sec}$ after the ultraviolet light was shuttered; however, all subjects reported that the stimuli were easily visible. Due to the low luminance of the background (measured with ultraviolet unshuttered), the contrasts were very high even after this time lapse.

\section{Results}

The mean illusions averaged over start positions and subjects, together with standard errors, appear in Table 1. A two-way analysis of variance with repeated measures on both $I$ and $T$ showed significant $I$ and $T$ effects $[F(2,28)=23.22, p<.01 ; F(2,28)$ $=4.66, \mathrm{p}<.025$, respectively] for the direct effect, whereas for the indirect effect, significant I effects only were observed $[F(2,28)=5.70, p<.01]$. For the direct effect, post hoc contrasts analysis (Scheffé, 1959) was performed to examine further the I and T effects. For I lengths of $1.0^{\circ}$ and $2.0^{\circ}$ visual angle, significant linear decreases were found with increases in $T$ line length ( $p<.05$ and .025 , respectively), whereas for each $\mathrm{T}$-line length, significant linear increases were found for increasing I-line length $(p<.01$, .01 , and .05 , respectively, for I-line lengths of $.5^{\circ}$, $1.0^{\circ}$, and $2.0^{\circ}$, respectively). Note that such contrast analysis within both $I$ and $T$ lengths involves nonorthogonality of contrasts, which is permissable in post hoc testing.
Post hoc contrasts analysis for the indirect effect revealed significant linear increases in the illusion with increases in I-line length for the T-line length of $2.0^{\circ}$ only $(\mathrm{p}<.01)$. Since post hoc analysis is meaningful only after significant $F$, $T$-line effects were not investigated.

\section{EXPERIMENT 2}

The effects of luminance change have been shown to be important both in psychophysical and electrophysiological experiments. Hoeppner (1974) varied average luminance of a light-dark border, keeping contrast constant at .91 from luminances of 11.10 to $.07 \mathrm{~cd} / \mathrm{m}^{2}$, and found that 52 out of a total of 56 cortical simple cells increased their firing rate as a result of increased stimulus luminance. Bisti et al. (1977) reported decreases in response amplitudes for $\mathrm{X}$ and $\mathrm{Y}$ on-center retinal ganglion cells, LGN cells, and simple and complex cortical cells for decreases in mean luminance of sinusoidal gratings. Effects of luminance changes have not yet been reported for hypercomplex cells. However, for the sample of cells reported, while the tuning curves for orientation maintained their shape at various levels of mean luminance, the overall activity of the cells went up, thus perhaps increasing the inhibitory input to other cells with which they have contact. Thus, increased inhibitory (and therefore disinhibitory) interaction should lead to increased effects reliant upon such interaction, and, if orientation interactions are indeed of this nature, luminance changes should change the size of the illusory effects.

Parker (1974) reported changes in the size of the direct effect with changes in luminance of both $T$ and I lines, with increases in I-line luminance resulting in increases in the direct effect and increases in Tline luminance resulting in decreases in the direct effect. He did not test for changes in the indirect effect, believing that it did not occur in the illusion. Tolhurst and Thompson (1975) changed contrast of a sine-wave grating generated on an oscilloscope screen and found that changes in the direct effect resulted with changes in contrast (keeping average luminance constant). However, changing contrast on an oscilloscope screen can be accomplished either 
by changing depth of modulation for constant average luminance, as done by Tolhurst and Thompson (which changes luminance of bright and dark bars), or by keeping modulation depth constant and changing average luminance, which also clearly changes luminance of bright and dark bars. Thus, the effects of luminance might possibly be confounded with the effects of contrast. Wallace (1975) investigated the effects of contrast change on the Zollner illusion by preparing different stripe displays photographically and presenting them under a constant illumination of $400 \mathrm{~cd} / /^{2}$. Since he used black lines on a white background for test and inducing stimuli, to decrease contrast (for constant brightness of background) he actually increased dark bar luminance. Thus, his method for changing contrast cannot separate the effects of luminance and contrast. Since contrast clearly depends upon luminance, and since Parker's experiment is not presented in sufficient detail to determine exactly whether contrast also changed, it is desirable to investigate the effects of luminance change for constant contrast.

\section{Method \\ Apparatus. In order to test the effects of luminance changes on the direct effect, lines constructed of strips of yellow PVC tape were interposed midway between $T$ and $C$, which then lay to the right and left of them, respectively. The induction line of the previous experiment was removed from the display (see Figure $1 \mathrm{~b}$ for stim- ulus configuration). The lines were oriented $10^{\circ}$ clockwise (CW) and counterclockwise (CCW) from vertical, and were constructed so as to be identical to the I line of Experiment 1; they intersected at their midpoints, which were on the same horizontal plane as the centers of T and C. Small strips of Polaroid filter were constructed of identical dimensions to the lines so that by laying strips of filter over the $\mathrm{CCW}$ line, its luminance could be changed without affec- ting luminances of other parts of the display. The distance between the centers of $\mathrm{T}, \mathrm{C}$, and the other two lines was $3.06^{\circ}$ visual angle. \\ Procedure. The subjects' task was either to set $C$ parallel to the $\mathrm{CW}$ line or CCW line in the absence of $\mathrm{T}$, or to set $\mathrm{T}$ parallel to the $\mathrm{CW}$ or CCW line in the absence of $\mathrm{C}$, with $\mathrm{T}$ or $\mathrm{C}$ occluded by small strips of black nonreflective tape. The perceived orientation of each of the $\mathrm{CW}$ and $\mathrm{CCW}$ lines was measured alone, in the presence of the other line, and with various luminance reductions of the $\mathrm{CCW}$ line, these conditions occurring in random order. Fifteen subjects were instructed to fixate the centers of the $\mathrm{CW}$ and $\mathrm{CCW}$ lines and were permitted to bracket. Within the conditions, the four start positions occurred in random order, with rest periods occurring after every eight settings.}

Luminance and contrast. Luminances of the $\mathrm{CW}$ line, $\mathrm{T}$, and $\mathrm{C}$ were constant at $2.06,4.91$, and $5.94 \mathrm{~cd} / \mathrm{m}^{2}$, respectively, while the background luminance was $.014 \mathrm{~cd} / \mathrm{m}^{2}$, thus making the contrasts $.986, .994$, and .995 , respectively. The luminances of the CCW line with strips of Polaroid filter were $1.99,1.23, .47$, and $.19 \mathrm{~cd} / \mathrm{m}^{2}$, thus giving contrasts of $.986, .977, .942$, and .863 , respectively. The apparatus would not permit exact equalizing of contrasts for each luminance level of the $\mathrm{CCW}$ line.

\section{Results}

The results of Experiment 2 appear in Table 2; means are averaged over start positions and subjects. Trend analysis using orthogonal polynomials resulted in linear trends in the conditions where $T$ was set parallel to the $\mathrm{CW}$ line $[\mathrm{F}(1,40)=12.77, \mathrm{p}<.01]$ and $C$ was set parallel to the CW line $[F(1,40)=$ $28.39, p<.001]$, as well as a significant cubic trend in this latter condition $[F(1,40)=5.91, p<.025]$. This significant cubic trend reflects a plateau in the illusion between $\mathrm{CCW}$ luminances of 1.23 and $.47 \mathrm{~cd} / \mathrm{m}^{2}$, and may indicate that the increase between these luminances is not sufficient to increase the effect significantly. All other trends were not significant ( $p>.05$ in each case).

Since the luminance change from 1.99 to $1.23 \mathrm{~cd} / \mathrm{m}^{2}$ is accompanied by a contrast change from .986 to .977 and the luminance change from .47 to $.19 \mathrm{~cd} / \mathrm{m}^{2}$ is accompanied by a contrast change from .942 to .863 , the question may be raised as to whether the change in magnitude of the illusion is a function not of luminance, but of contrast. This is unlikely, however, since the contrast change occurs for highcontrast stimuli, and Tolhurst and Thompson (1975) reported data showing little change in the size of the illusion for an I-grating contrast of approximately .7 and a T-grating contrast above approximately .3 (see Figures 2 and 3, pp. 969 and 970, Tolhurst \& Thompson, 1975). Since all contrast values of the $\mathrm{CW}$ and $\mathrm{CCW}$ lines were above these values, the change in the size of the illusion is probably due to the relative luminance changes of the $\mathrm{CCW}$ line.

\section{EXPERIMENT 3}

\section{Method}

To ascertain the effects of luminance on the indirect effect, Experiment 2 was repeated with lines oriented $35^{\circ} \mathrm{CW}$ and $\mathrm{CCW}$

Table 2

Effect (in Degrees) of Luminance Change of the CCW Line on the Direct Effect

\begin{tabular}{|c|c|c|c|c|c|c|c|c|}
\hline & \multicolumn{8}{|c|}{ Luminance of CCW Line $\left(\mathrm{cd} / \mathrm{m}^{2}\right)$} \\
\hline & \multicolumn{2}{|c|}{.19} & \multicolumn{2}{|c|}{.47} & \multicolumn{2}{|c|}{1.23} & \multicolumn{2}{|c|}{1.99} \\
\hline & Mean & SE & Mean & SE & Mean & SE & Mean & SE \\
\hline $\begin{array}{l}\text { Set } T \text { parallel to } C W \text { line } \\
\text { Set } T \text { parallel to } C C W \text { line } \\
\text { Set C parallel to } C W \text { line } \\
\text { Set } C \text { parallel to } C C W \text { line }\end{array}$ & $\begin{array}{r}.16 \\
-1.15 \\
-.54 \\
-.75\end{array}$ & $\begin{array}{l}.24 \\
.46 \\
.24 \\
.48\end{array}$ & $\begin{array}{r}.45 \\
-1.44 \\
1.07 \\
-\quad .65\end{array}$ & $\begin{array}{l}.15 \\
.42 \\
.35 \\
.34\end{array}$ & $\begin{array}{r}.48 \\
-1.26 \\
-.90 \\
-.75\end{array}$ & $\begin{array}{l}.24 \\
.31 \\
.38 \\
.24\end{array}$ & $\begin{array}{r}1.16 \\
-.94 \\
2.07 \\
-.55\end{array}$ & $\begin{array}{l}.17 \\
.37 \\
.34 \\
.26\end{array}$ \\
\hline
\end{tabular}

Note-Since a direct effect measured on the $C W$ line is due to the effect of the CCW line, these effects are positive, whereas direct effects measured on the $\mathrm{CCW}$ line are conversely negative. 
from vertical replacing the $10^{\circ}$ lines. Again $\mathrm{T}$ and $\mathrm{C}$ were used to measure the perceived orientation of these lines; however, due to the design of the mechanical apparatus, it was not possible to measure the perceived orientation of both the $\mathrm{CW}$ and $\mathrm{CCW}$ lines with both $T$ and $C$ as in Experiment 2. Since setting $C$ parallel to the $\mathrm{CW}$ line and setting $\mathrm{T}$ parallel to the $\mathrm{CCW}$ line gave largest effects in Experiment 2, it was decided to use only these conditions in Experiment 3. Since the size of the indirect effect is smaller than the direct effect, any differences in illusion sizes might not be detected if the sample size was too small. Consequently, the sample size was increased to 20 , which gives similar power to the statistical test used in Experiment 2 for a reduced effect size (see, for example, Cohen, 1969, for computational procedures). Apart from these differences, Experiment 3 was identical to Experiment 2.

\section{Results}

The results of Experiment 3 appear in Table 3; means are averaged over start positions and subjects. Trend analysis using orthogonal polynomials showed a significant linear trend when $\mathrm{C}$ was set parallel to the $\mathrm{CW}$ line $[\mathrm{F}(1,57)=4.46, \mathrm{p}<.05]$. No other trends were significant.

\section{DISCUSSION}

It has been established that both direct and indirect effects occur when the method of measurement involves a matching procedure as well as vertical setting, when the test line is in the oblique as well as the vertical meridian, and when the lateral separation of $\mathrm{T}$ and $\mathrm{C}$ is $7^{\circ}$ visual angle, irrespective of whether subjects fixate the $\mathrm{T}$ or $\mathrm{C}$ lines (O'Toole \& Wenderoth, 1977). The present experiments also show that the effects may be contingent on both length and luminance of induction stimuli. Experiment 1 showed, for the direct effect, that increasing the length of the I line increased the size of the illusion for all $\mathrm{T}$-line lengths, whereas for I-line lengths of $1.0^{\circ}$ and $2.0^{\circ}$ visual angle, increasing the $\mathrm{T}$ line resulted in decreases in the size of the illusion. Systematic effects for the indirect effect were not so obvious. However, for a T-line length of $2.0^{\circ}$, a linear increase in the size of the illusion occurred for increases in I-line length.

Experiments 2 and 3 partially duplicate the results of Parker (1974) in that changes in the size of the tilt illusion were observed for changes in luminance of an induction stimulus. However, Parker observed changes in perceived orientation of a test line which itself changed in luminance relative to a constant luminance induction line, an effect not observed in the present experiments. It may not have been possible to detect such changes in the present experiments because of the limited range of luminance change $\left(1.99\right.$ to $0.19 \mathrm{~cd} / \mathrm{m}^{2}$, or 0 to $-1.02 \log$ relative luminance); Parker used a much larger range ( 0 to $-2.0 \mathrm{log}$ relative luminance). Lower luminances were not used in the present experiments in order to maintain high contrast of the $\mathrm{CCW}$ line. However, Parker did not test for changes in the indirect effect, which were observed in Experiment 3.

The results of the first three experiments are generally in accord with predictions based on a lateral inhibitory and disinhibitory account of the tilt illusion. However, a psychophysical test of this inhibitiondisinhibition hypothesis would be to inhibit the inhibitory influence of $I$ on $T$ and thus reduce the direct effect, or inhibit the disinhibitory influence of $I$ on $T$ and thus reduce the indirect effect. That the direct effect can be reduced by the addition of a third line to the display has been demonstrated by Carpenter and Blakemore (1973). However, they did not demonstrate any phenomena in connection with the indirect effect, which indeed they failed to obtain. It was the purpose of the remaining experiments of the paper to investigate whether disinhibition of the indirect effect could be obtained by addition of a third line to the display at the appropriate orientation, and to manipulate length and luminance of this line to determine if effects similar to those observed in the prior experiments could be observed here.

\section{EXPERIMENT 4}

\begin{abstract}
Method
The first experiment of this series undertook to establish whether "disinhibition" of the direct and indirect effects could be obtained. Since the maximum tilt illusion occurs for an I-T separation of between $10^{\circ}$ and $20^{\circ}$ (e.g., Carpenter \& Blakemore, 1973; Logan, 1962; O'Toole \& Wenderoth, 1977), and if, as has been argued, inhibition underlies the direct effect, then for maximum inhibition of the I line, the disinhibiting line should be approximately $20^{\circ}$ from it. Thus, to investigate disinhibition of the direct effect, the $\mathrm{T}$ line was vertical, the I line was $20^{\circ} \mathrm{CW}$ from vertical, and the third line (disinhibiting or $\mathrm{D}$ line) was $40^{\circ}$ from vertical. To
\end{abstract}

Table 3

Effect (in Degrees) of Luminance Change of the CCW Line on the Indirect Effect

\begin{tabular}{|c|c|c|c|c|c|c|c|c|}
\hline & \multicolumn{8}{|c|}{ Luminance of $\mathrm{CCW}$ Line $\left(\mathrm{cd} / \mathrm{m}^{2}\right)$} \\
\hline & \multicolumn{2}{|c|}{.19} & \multicolumn{2}{|c|}{.47} & \multicolumn{2}{|c|}{1.23} & \multicolumn{2}{|c|}{1.99} \\
\hline & Mean & SE & Mean & SE & Mean & SE & Mean & SE \\
\hline $\begin{array}{l}\text { Set } T \text { parallel to } C C W \text { line } \\
\text { Set } C \text { parallel to } C W \text { line }\end{array}$ & $\begin{array}{r}.51 \\
-.16\end{array}$ & $\begin{array}{l}.26 \\
.21\end{array}$ & $\begin{array}{r}.30 \\
-.28\end{array}$ & $\begin{array}{l}.23 \\
.22\end{array}$ & $\begin{array}{r}.47 \\
-.40\end{array}$ & $\begin{array}{l}.23 \\
.22\end{array}$ & $\begin{array}{r}.45 \\
-.58\end{array}$ & $\begin{array}{l}.18 \\
.14\end{array}$ \\
\hline
\end{tabular}

Note-Indirect effects are acute angle contraction effects, so those measured on the CCW line are positive, whereas those measured on the $C W$ line are negative. 
investigate disinhibition of the indirect effect, the $T$ line was vertical, the I line was $70^{\circ} \mathrm{CW}$ from vertical, and the $\mathrm{D}$ line was horizontal.

The $D$ line was constructed so as to be identical to the I line, and was placed on the display so that the centers of $T, I$, and $D$ coincided spatially (see inset of Figure 3). The distance between the centers of $T$ and $C$ was again $3.83^{\circ}$ visual angle.

Luminance and contrast. Luminances of $C, T, I$, and $D$ were $3.39,2.81,1,18$, and $1.06 \mathrm{~cd} / \mathrm{m}^{2}$. each measured by Spectra Pritchard photometer with a 6-min of arc aperture; the background luminance of the flat black apparatus was $.0045 \mathrm{~cd} / \mathrm{m}^{2}$ measured with a $2^{\circ}$ aperture. Thus, contrasts of the stimuli were again high at $.997, .996, .993$, and .992 , respectively.

Procedure. One group of 15 subjects fixated the center of $T$ and set $C$ parallel to $T$ in the absence of $D$ and 1 (pretest), in the presence of I (illusion), and in the presence of $I$ and $D$ (dis-illusion), all conditions occurring in random order. Each subject participated in two sessions, in one of which the direct-effect conditions were presented and in the other the indirect-effect conditions. There was a 10-min rest period between sessions, and the order of sessions was determined randomly.

\section{Results}

The results appear in Figure 2; each point represents the test-minus-pretest means of 45 subjects averaged over four start positions; vertical bars represent \pm SEM. The magnitudes of both direct and indirect effects ( $D$ absent) were significantly different from the dis-illusion cases [D present; $\mathrm{t}(14)=2.189, \mathrm{p}<.05$; $\mathrm{t}(14)=4.558, \mathrm{p}<.001$, respectively, for direct and indirect effects].

Thus, the results show that the addition to the display of a third line at $20^{\circ}$ to the induction line results in significant reduction in the magnitude of the illusion for both direct and indirect effects.

\section{EXPERIMENT 5}

Experiment 1 showed that changes in illusion magnitude occurred when the length of the induction line was changed. It was argued that these effects occur due to changes in the inhibitory effect of the induction line. Experiment 5 was conducted to determine if a similar reduction in length of the $D$ line caused an increase in the size of the illusion, via a reduction in the inhibitory effect of $D$ on $I$, and thus a reduction in the disinhibitory effect of $D$ on $T$.

\section{Method}

Fifteen subjects were tested under each of 12 conditions: a pretest (I and D absent), a test of the direct effect and of three disinhibiting conditions, and a test of the indirect effect and of six disinhibiting conditions. For the direct-effect test, I was $20^{\circ} \mathrm{CW}$ from vertical and $\mathrm{D}$ was absent; in the disinhibiting conditions, I was $20^{\circ}$ and $\mathrm{D}$ was $40^{\circ} \mathrm{CW}$ from vertical. For the indirect-effect test, 1 was $70^{\circ} \mathrm{CW}$ from vertical and $\mathrm{D}$ was absent; in the disinhibiting conditions, I was $70^{\circ}$ and $\mathrm{D}$ either $50^{\circ}$ or $90^{\circ} \mathrm{CW}$ from vertical (to determine if a $\mathrm{D}$ line at $50^{\circ}, 20^{\circ}$ from $\mathrm{I}$ but between I and $T$, had similar effects to a $D$ line at $90^{\circ}$, also $20^{\circ}$ from $I$ but on the opposite side from $T$ ). For all disinhibiting conditions, there were three lengths of $D-.5^{\circ}, 1.0^{\circ}$, and $2.0^{\circ}$ visual angle. The different lengths of $D$ were made possible by partial occlusion of $D$ with small strips of black nonreflecting tape. The 12 conditions were run in random order, and subjects again set $C$ parallel to $T$ while fixating the center of $\mathrm{T}$.

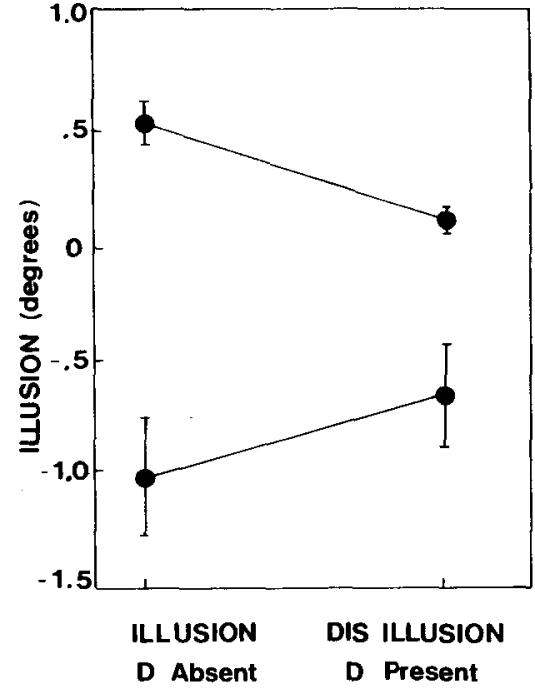

Figure 2. Dis-illusion demonstration: the presence of a third line $20^{\circ}$ from the I line reduces the illusion; direct effects are negative, and indirect effects are positive.

\section{Results}

The results appear in Figure 3; means are averaged over start positions and subjects, with vertical bars representing \pm SEM. Trend analysis using orthogonal polynomials indicates a significant linear trend in both the direct and indirect effect ${ }^{1}$ conditions $[F(1,42)$ $=13.42, \mathrm{p}<.01 ; \mathrm{F}(1,84)=9.91, \mathrm{p}<.01$, respectively]. None of the higher order trends was significant ( $p>.05$ in every case). Perusal of Figure 3 reveals that the linear trend is a decrease in illusion magnitude with increases in D-line length, which mirrors the effect of length found in Experiment 1, and is concordant with predictions.

\section{EXPERIMENT 6}

\section{Method}

In order to test the effects of luminance decreases on the disinhibitory effects of the D line, small strips of Polaroid filter were placed over the $D$ line, which decreased its luminance from $1.06 \mathrm{~cd} / \mathrm{m}^{2}$ (with no filter) to $.27 \mathrm{~cd} / \mathrm{m}^{2}$ (with one strip) to $.09 \mathrm{~cd} / \mathrm{m}^{2}$ (with two strips), which gave contrasts of $.992, .968$, and .904 , respectively. The apparatus would not permit equalizing of contrast values. A new group of 15 subjects again adjusted $C$ to be parallel to $T$ in the absence of $I$ and $D$ (pretest) and in the presence of I (illusion) and D and I together (dis-illusion) for two orientations of $I$ of $20^{\circ} \mathrm{CW}$ from vertical, and for the disinhibition of the indirect effect. D was oriented $50^{\circ} \mathrm{CW}$ from vertical, as this condition also results in reduction of the indirect effect (as found in Experiment 5). The order of presentations was randomized; subjects fixated the center of $T$.

\section{Results}

Results appear in Figure 4; means are averaged over start positions and subjects, and vertical bars represent \pm SEM. The illusion has been plotted as a function of the logarithm of the D-line luminance. Since the contrast of the lowest D-line luminance was high (.904), any change in the size of the illu- 


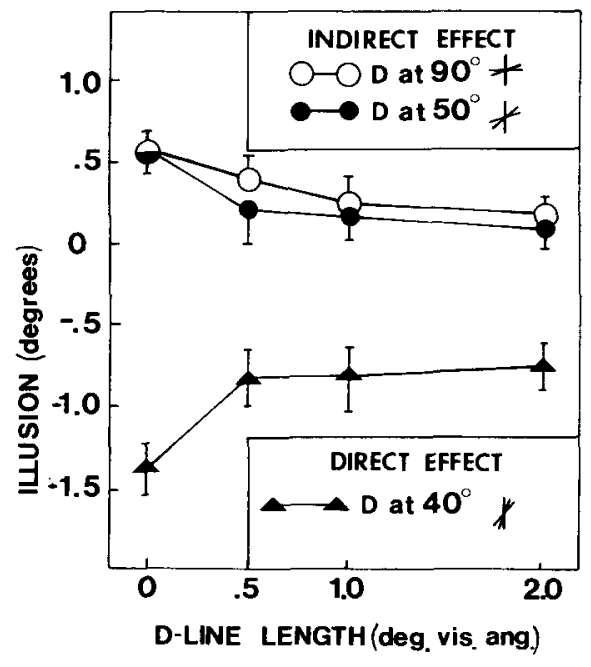

Figure 3. Illusion magnitude as a function of $D$ line length for the direct effect (filled trianiges) and indirect effect for two orientations of $\mathrm{D}$ of $50^{\circ}$ (filled circles) and $90^{\circ}$ (open circles).

sion may have been due to the addition of $\mathrm{D}$ at any luminance. Consequently, trend analysis using orthogonal polynomials used only the conditions in which D was present, in order to test for trend as the luminance of $\mathrm{D}$ was increased. This revealed a significant linear trend only, for both direct and indirect effect conditions $[F(1,28)=8.02, p<.01 ; F(1,28)$ $=11.76, \mathrm{p}<.01$, respectively]. Clearly, the luminance of the D line has an effect on the size of the illusion: As the luminance increases, the illusion is reduced. This mirrors the effects of luminance found in Experiments 2 and 3 .

\section{EXPERIMENT 7}

If inhibitory interaction is the process underlying the tilt illusion, then it may be possible to use the paradigm of the tilt illusion to delineate the extent of this inhibition in the orientation domain. If the $D$ line has its effect on the $\mathrm{T}$ line via inhibitory interaction with the I line, and if this inhibitory interaction is a function of the separation of the lines in the orientation domain, then, if the D line is added to the $T$ and $I$ lines and varied in orientation, there may come a point where the illusion returns full strength. This orientation separation of $I$ and $D$ will thus delineate the extent of the inhibitory effect of D on I, and thus the tuning width of lateral inhibition in the orientation domain for a vertical $\mathrm{T}$ line.

\section{Method}

Fifteen subjects again set $C$ parailel to $T$ in the absence (pretest) and then in the presence (illusion) of $I$, and then in the presence of $I$ and $\mathrm{D}$. T was vertical, I was $20^{\circ} \mathrm{CW}$ from vertical, and $\mathrm{D}$ was varied from $30^{\circ}$ to $90^{\circ} \mathrm{CW}$ from vertical in $10^{\circ}$ steps. These condi- tions were presented in random order. The subjects fixated the center of $T$.

\section{Results}

The results appear in Figure 5; each point represents the mean of 15 subjects averaged over the four start positions and corrected for pretest settings. Vertical bars represent \pm SEM.

Trend analysis using orthogonal polynomials revealed significant cubic and quartic trends $[F(1,98)$ $=15.96, \mathrm{p}<.01 ; \mathrm{F}(1,98)=6.23, \mathrm{p}<.05$, respectively], which reflect the fall in the illusion for the $10^{\circ}$ and $20^{\circ} \mathrm{I}-\mathrm{D}$ orientation separation and the rise to $30^{\circ}$.There is also a slight fall for I-D separation of $70^{\circ}$, which may explain the significant quartic trend. This latter result is unfortunately inconsistent with the model, since a D line $70^{\circ}$ from an I line should have a disinhibitory effect on it, and consequently enable the I line to exert a greater inhibitory influence upon the test line, thus, if anything, increasing the size of the illusion. It is difficult to reconcile this result with the model, as well as the fact that the illusion was decreased for all orientations of the $\mathrm{D}$ line. In order to determine whether a significant decrease occurred, a Scheffé procedure for post hoc analysis (Scheffé, 1959) was performed, pairwise comparisons between the size of the illusion when D was absent and when $D$ was present were carried out for all orientations of $D$. A significant difference occurred for the I-D separation of $20^{\circ}(\mathrm{p}<.01)$; all other pairs were not significantly different $(p>$ .05 in each case). Thus, while the drop in the magnitude of the illusion at the I-D separation of $70^{\circ}$ may account for the significance of the quartic trend (which was an unexpected result), this drop was not significantly different from zero.

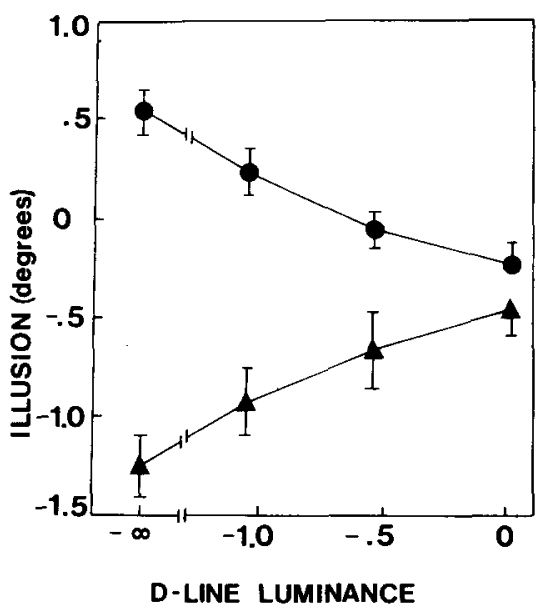

$$
\log _{10} \mathrm{~cd} / \mathrm{m}^{2}
$$

Figure 4. Illusion magnitude as a function of the logarithm of D line luminance for the direct effect (triangles) and indirect effect (circles). 


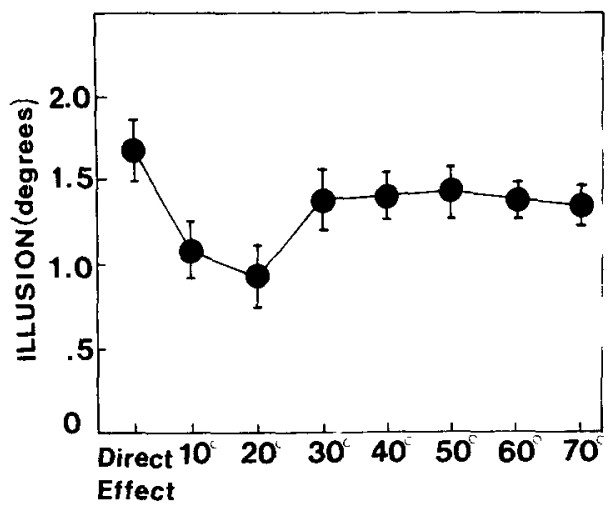

I-D ANGULAR

SEPARATION

Figure 5. Angular function for changes in $D$ line orientation for a vertical $T$ line and $I$ line at $20^{\circ}$ from vertical. Direct effects are plotted as positive.

\section{GENERAL DISCUSSION}

The aim of the experiments reported here was to test predictions based on a lateral inhibitory and disinhibitory account of the tilt illusion. It was hypothesized that, if changes in length and luminance of stimuli resulted in changed ouput of cortical units responsive to such stimuli, then concomitant changes in inhibitory and disinhibitory interactions should result. Changes in length and luminance have been shown to affect the activity of cortical units, and thus, changes in these parameters were predicted to result in changes in illusory effects. Such changes were observed in Experiments 1, 2, and 3, where reductions in length and luminance of the induction line resulted in decreased illusion.

It was further hypothesized that, if the reduction in the size of the tilt illusion that occurs by addition of the $\mathrm{D}$ line is due to a reduction in the inhibitory influence of I on T, via an inhibitory influence of D on $\mathrm{I}$, then similar reductions in the length and luminance of $\mathrm{D}$ should result in decreases in the reduction of the illusory effects. This was observed in Experiments 5 and 6 , and thus these results add further support to the model. As Carpenter and Blakemore (1973) and Wenderoth and Curthoys (1974) have found before, I and D clearly were not additive in their effects on $\mathrm{T}$. That the maximum reduction of the direct effect occurred for an 1-D separation of $20^{\circ}$ in Experiment 7 adds weight to the disinhibition argument, since, if effects were additive, the illusion should return full strength at this point, since only a small direct effect occurs for a line $40^{\circ}$ from a test line. In spite of the overall reduction in the magnitude of the direct effect for all orientations of D in this experiment, the size of the illusion reached asymptote at an I-D separation of approximately $30^{\circ}$ (see Figure 5), which would indicate that the extent of the lateral inhibitory processes postulated to be responsible for the effects is approximately $30^{\circ}$.

It is of interest to note two things here: first, data of the same form appear in the work of Carpenter and Blakemore (1973), where the angular function of the disinhibiting line first falls, then rises, then falls again. Their work indicated a maximum disinhibitory effect at approximately $10^{\circ}$ I-D separation, less than half of that obtained here. Second, the data of Blakemore and Tobin (1972) shows inhibition in the orientation domain at the single-cell level for orientation differences of approximately $60^{\circ}$, which is double the estimate found here, and is certainly much more than the estimate derivable from the data of Carpenter and Blakemore (1973; see Figures 10 and 11). However, apart from differences that may exist between cat and human cortical integration, another fact that makes questionable the applicability of the Blakemore and Tobin data to the results of the present experiments is that this inhibition appears to come from neurons that lie outside the retinal locus of that neuron from which the recording was made. Nelson and Frost (1976) selected units that were optimally stimulated by a small central bar sweeping back and forth across the discharge center of cat cortical receptive fields of simple and hypercomplex cells. They then swept an inhibiting grating annulus back and forth; the grating had an inner diameter of $5^{\circ}$ or $10^{\circ}$ and surrounded, but was remote from, the cells' receptive fields. The presence of the grating inhibited the discharge elicited by the bar stimulus. Thus, inhibition between orientation-sensitive units has been demonstrated in complex (Blakemore \& Tobin, 1972) and in simple and hypercomplex cells (Nelson \& Frost, 1976). It is interesting to note that in both reports there was also a region beyond $60^{\circ}$ where the output of the cell was above the maximum discharge elicited in the $a b$ sence of the inhibiting grating (i.e., a disinhibiting effect). While such data are frequently cited as examples of inhibitory interaction which may account for orientation effects (e.g., Carpenter \& Blakemore, 1973; Tolhurst \& Thompson, 1975), it is difficult to see the exact connection of this data with the psychophysical evidence on contour interaction in the orientation domain, since, if this inhibition comes from outside the receptive field of the neuron under test, it must come from units with receptive fields that do not have spatial overlap on the retina. Thus, if neurons that subserve different parts of the visual field can interact, and this interaction occurs for up to $10^{\circ}$ visual angle separation, then the psychophysical implication is that lines that are spatially separated may still affect each other. That this does not occur has been previously documented (Tolhurst \& Thompson, 1975; Virsu \& Taskinen, 1975; Wallace, 1969), the critical distance of interaction being an order of magnitude less than that found by Nelson and Frost (1976). Perhaps what is required is an investigation of the properties of cells when intersecting 
lines such as occur in the tilt illusion are exposed to the same cell's receptive field. Such complex analysis may give some clue as to the change in output of a single cell as it is excited at its best orientation and at the same time inhibited by the output of other cells sensitive to different orientations but subserving the same part of the visual field. Burns and Pritchard (1971), in fact, reported failure to find a peak shift in the orientation tuning of a cell when excited by a line or a $30^{\circ}$ angle pattern; however, they were not able to determine peak shifts of less than approximately $3^{\circ}$. They did find changes in peak amplitude of poststimulus histograms for an angle pattern (Figure 4, p. 607) when compared with a single line, and that, to account for illusions involving orientation interactions (e.g., the tilt and Zöllner illusions), a peak shift in the output of a single cell is not required: an overall reduction or increase may be sufficient to change the pattern of firing across an entire population, which may be then interpreted as a shift in the orientation of the stimulus. Apart from the fact that Burns and Pritchard unfortunately used a $30^{\circ}$ angle pattern, which gives quite small illusory effects, their data are more applicable to psychophysical investigations of orientation interaction than the single cell data either of Blakemore and Tobin (1972) or Nelson and Frost (1976).

A number of studies have suggested that illusions produced by abutting and intersecting line figures are not distortions of perceived orientation of the whole line, but a bowing effect of the lines at the point of abuttal or intersection (Chiang, 1968, 1975; Schilder \& Weschsler, 1936; Wenderoth, Beh, \& White, 1978a, 1978b), Burns and Pritchard (1971) also suggested that the distortion produced by their angle pattern was one of bowing (see Figure 6, p. 610), since on varying the separation of two lines passed successively across the receptive field, the position of the maximum response first shifted to one side of the discharge center, then to the other. When they used a $30^{\circ}$ angle pattern and varied the locus of the tip, a similar result occurred (Figure 7, p. 611). Next they varied the distance between two parallel lines and found that the maximum response first rose, then fell, then returned to the level of response when only one line was presented. Phelps (1974), however, reported various kinds of interaction produced by moving parallel lines: when the interline separation was varied, $40 \%$ of units showed inhibition only, $11 \%$ showed enhanced output only, $14 \%$ showed inhibition then enhancement, $17 \%$ showed the reverse, with $6 \%$ and $3 \%$, respectively, showing inhibition/ enhancement/inhibition and enhancement/inhibition/ /enhancement, while $9 \%$ of the cells showed no effect of varying interline separation. The results of Burns and Pritchard, then, appear to bear more on the effects of lateral separation in the spatial domain than on angular separation in the orientation domain, to which the effects of various angle patterns would be more relevant. The predictions for the coding of angles and interactions between orientations from the data of Burns and Pritchard must be viewed as tentative at best, since opposite predictions can be made from each of the types of response observed by Phelps (1974), of which the type of response reported by Burns and Pritchard (1971) appears to be a subset.

Wenderoth, Beh, and White (1978a) suggested that the orientation of a line is signaled by the weighted ouputs of orientation analyzers which process short sublengths of a line. Such sublength analyzers are presumed to process lengths of about $9 \mathrm{~min}$ of arc (Andrews, 1967a, 1967b; Andrews, Butcher, \& Buckley, 1973; Bacon \& King-Smith, 1977; Vassilev \& Penchev, 1976). At the point of abuttal or intersection, analyzers reponsive to the test line are more affected by the presence of the inducing line (perhaps by a process of lateral inhibition) than are analyzers further away. Thus, different-sized illusions should be measured for different lengths of test line (i.e., with short test lines giving the largest illusion) or for different methods of measuring perceived orientation, since, for example, dot setting would reflect the perceived orientation of the bowed end of the line, while parallel matching (or vertical setting, or staircase methods) would reflect an averaging over subunits. Thus for equal-sized test and comparison lines, when the method of measurement is parallel matching, short test lines should give larger illusions than long test lines for constant-sized induction lines. This occurred in Experiment 1 for the direct effect for Iline lengths of $1.0^{\circ}$ and $2.0^{\circ}$, but not for other conditions. Thus, increasing the induction line length for constant test line length may simply involve more sublength analyzers and thus increase the inhibitory effect on analyzers signaling the presence of the test line, rather than change the output of any one analyzer. This hypothesis, however, cannot explain the results of Experiments 2, 3, and 6, since in each of these experiments the length of all lines was constant.

Hoeppner (1974) reported that similar firing rates could be obtained from simple cortical cells with either changes in orientation or changes in stimulus luminance. Psychophysically, this might imply that similar angular distortions should be possible with either changes in orientation or changes in stimulus luminance, and, as the present report suggests, changes in stimulus length also. Movshon and Blakemore (1973) have already reported "equivalent contrast" functions for orientation and spatial frequency, which results in the same contrast threshold elevation for cortical "channels," thus indicating an equivalence of orientation and spatial frequency in the activity of cortical mechanisms responsible for threshold ele- 
vation. Hoeppner's results are clear support for the "multi-channel neurone" (Blakemore, 1975), and the present report suggests that there may be many equivalences in the coding of orientation in the visual system.

\section{REFERENCES}

ANDREWs, D. P. Perception of contour orientation in the central fovea. Part I: Short lines. Vision Research, 1967, 7, 975-997. (a)

ANDrews. D. P. Perception of contour orientation in the central fovea. Part 1I: Spatial integration. Vision Research, 1967, 7. 999-1013. (b)

Andrews, D. P., Butcher, A. K., \& Buckley, B. R. Acuities for spatial arrangement in line figures: Human and ideal observers compared. Vision Research. 1973, 13, 599-620.

BACON. I.. \& KING-SMITH, P. E. The detection of line segments. Perception, 1977, 6, 125-131.

Bisti, S.. Clement, R:, Maffei, L., \& Mecacci, L. Spatial frequency and orientation tuning curves of visual neurones in the cat: Effects of mean luminance. Experimental Brain Research, 1977, 27, 335-345.

Blakemore, C. Central visual processing. In M. S. Gazzaniga \& C. Blakemore (Ed.), Handbook of psychobiology. New York: Academic Press, 1975.

Blakemore, C., \& ToBin, E. A. Lateral inhibition between orientation detectors in the cat's visual cortex. Experimental Brain Research, 1972, 15, 439-440.

Burns, B. D., \& Pritchard, R. Geometrical illusions and the responses of neurones in the cat's visual cortex to angle patterns. Journal of Physiology, 1971, 213, 599-616.

CARPENTER, R. H. S., \& BLAKEMORE, C. Interactions between orientations in human vision. Experimental Brain Research, 1973, 18. 287-303.

ChIANG. C. A new theory to explain illusions produced by crossing lines. Perception \& Psychophysics, 1968, 3, 174-176.

Chiang, C. A theory of the Poggendorff illusion. Japanese Psychological Research, 1975, 17, 111-118.

COHEN, J. Statistical power analysis for the behavioural sciences. New York: Academic Press, 1969.

DAY, R. H. Inappropriate constancy explanation of spatial distortions. Nature, 1965, 207. 891.893.

GiBson. J. J. Adaptation, aftereffect, and contrast in the perception of tilted lines. 11: Simultaneous contrast and the areal restriction of the aftereffect. Journal of Experimental Psychology, $1937,20,553-569$.

Gibson, J. J., \& Radner, M. Adaptation, aftereffect, and contrast in the perception of tilted lines. I: Quantitative studies. Journal of Experimental Psychology, 1937, 20, 453-467.

Hartline, H. K., \& RatLifF, F. Inhibitory interactions of receptor units in the eye of Limulus. Journal of General Physiology, $1957,40,357-376$.

Henry, G. E., Bishop, P. O., \& Dreher, B. Orientation, axis and direction as stimulus parameters for striate cells. Vision Research, 1974, 14, 767-777.

Henry, G. H., Dreher, B., \& Bishop, P. O. Orientation specificity of cells in cat striate cortex. Journal of Neurophysiology, 1974, 37, 1394-1409.

HOEPPNER. T. J. Stimulus analysing mechanisms in the cat visual cortex. Experimental Neurology, 1974, 45, 257-267.

LOGAN. J. An examination of the relationship between visual illusions and aftereffects. Unpublished doctoral dissertation. University of Sydney, Australia, 1962.

Movshon, J. A., \& Blakemore, C. Orientation specificity and spatial selectivity in human vision. Perception, 1973, 2, $53-60$.

Muir, D., \& Over, R. Tilt aftereffects in central and peripheral vision. Journal of Experimental Psychology, 1970, 85, 165-170.

Nakayama, K., \& Roberts, D. J. Line length detectors in the human visual system: Evidence for selective adaptation. Vision Research, 1972, 12, 1709-1713.
Nelson, J., \& Frost, B. Orientation selective inhibition from beyond the classic cortical receptive field. Neurosciences Abstracts, 1976, 2, Parts 1 and 2.

O'Toole, B. I., \& Wenderoth, P. M. The tilt illusion: Repulsion and attraction effects in the oblique meridian. Vision Research, 1977, 17, 367-374.

Over, R., Broerse, J., \& Crassini, B. Orientation illusion and masking in central and peripheral vision. Journal of Experimental Psychology, 1972, 96, 25-31.

Oyama, T. Deterninants of the Zöllner illusion. Psychological Research, 1975, 37, 261-280.

PARKer, D. M. Evidence for the inhibition hypothesis in expanded angle illusion. Nature, 1974, 250, 265-266.

Parlee, M. B. Visual backward masking of a single line by a single line. Vision Research, 1969, 9, 199.205.

Phelps, R. W. Effects of interaction of two moving lines on single unit responses in the cat's visual cortex. Vision Research, 1974, 14, 1371-1375.

SCHEFFÉ, H. The analysis of variance. New York: Wiley, 1959.

Schilder, P., \& Wechsler, D. The illusion of the oblique intercept. Journal of Experimental Psychology, 1936, 19. 747.757.

Tolmurst, D. J., \& Thompson, P. G. Orientation illusions and aftereffects: Inhibition between channels. Vision Research, $1975,15,967-972$.

Vassilev, A., \& Penchev, A. Spatial and temporal summation in the perception of lines. Vision Research, 1976, 16, 1329-1335.

VIRSU, V., \& TASKINEN, H. Central inhibitory interactions in human vision. Experimental Brain Research, 1975, 23, 65-74.

WALLACE, G. K. The critical distance of interaction in the Zöliner illusion. Perception \& Psychophysics, 1969, 5, 261-264.

Wallace, G. K. The effect of contrast on the Zöllner illusion. Vision Research, 1975, 15, 963-966.

Wenderoth, P. M., \& BeH, H. C. Component analysis of orientation illusions. Perception, 1977, 6, 57-75.

Wenderoth, P., Beh, H., \& White, D. Alignment errors to both ends of acute- and obtuse-angle arms. Perception \& Psychophysics, 1978, 23, 475-482. (a)

Wenderoth, P. M., Beh, H. C., \& White, D. G. Perceptual distortion of an oblique line in the presence of an abutting line. Vision Research, 1978, 18, 923-930. (b)

Wenderoth, P. M., \& Curthoys, I. S. On the non-additivity of visual tilt illusions. Quarterly Journal of Experimental Psychol. ogy, 1974, 26, 549-555.

Wenderoth, P. M. O'Toole, B. I., \& Curthoys, I. S. The effect of inducing line length on the magnitude of the tilt illusion and aftereffect. Australian Journal of Psychology, 1975, 26, 1-7.

Wenderoth, P. M., Rodger, R. S., \& Curthoys, I. S. Confounding of psychophysical errors and sensory effects in adjustment measures of spatial aftereffects. Perception \& Psychophysics, 1968, 4. 133-138.

\section{NOTE}

1. Since only one mean for the indirect effect was taken, this mean cannot be used in two independent sets of contrasts involving the six D-line conditions without rendering the contrasts nonorthogonal. To circumvent this, the analysis was done on all indirect effect groups with the means ordered thus: $2^{\circ} \mathrm{D}$ line at $50^{\circ}, 1^{\circ} \mathrm{D}$ line at $50^{\circ}, .5^{\circ} \mathrm{D}$ line at $50^{\circ}, \mathrm{D}$ line absent; $.5^{\circ} \mathrm{D}$ line at $90^{\circ}, 1^{\circ} \mathrm{D}$ line at $90^{\circ}, 2^{\circ} \mathrm{D}$ line at $90^{\circ}$, and the seven groups tested for trend. In this way, a significant quadratic trend would indicate linear trend for the $50^{\circ}$-oriented $\mathrm{D}$ line as well as for the $90^{\circ}$-oriented D line, provided that the cause for the significant quadratic trend was an elevation of the indirect effect mean (D line absent), which, in fact, occurred $[F(1,84)=9.92$, $\mathrm{p}<.01]$.

(Received for publication June 20, 1978; revision accepted January 9, 1979.) 